\title{
An insight of undergraduate medical education and residency programs in Brazil
} UMA VISÃo DA GRADUAÇÃo E DA RESIDÊNCIA MÉDICA NO BRASIL

Perhaps the medical practice in Brazil has never experienced moments as difficult as today's. We always had problems, such as the relationship with health insurance companies and career recognition, but there was never any doubt as to the quality and training of Brazilian doctors. The Brazilian medical practice has always been renowned for the quality of its undergraduate and residency programs, which produce professionals as qualified as any other in the so-called First World.

A reflection must be done: What happens when so many qualified professionals, renowned teachers and reputable medical organizations begin to question medical training?

Let's start our analysis with the job market for the newly graduated physician. There is no doubt that in recent years there has been an improvement in remuneration for medical graduates and a larger number of job vacancies compared to other professions. This led to an increased demand for medical courses, attracting the attention of educational institutions more concerned with profit than with the quality of teaching. These institutions began to impose the creation of new medical courses, and - for some time - it was possible to curb this trend by adopting a more serious educational policy that did not allow the indiscriminate opening of new courses. However, the current government policy came into line with these institutions and started to ratify the opening of new medical schools - if we can call them that - and some do not have any conditions to form medical professionals. Absurdly expensive courses began to appear without qualified teachers, without appropriate laboratories, and most of all without their own teaching hospitals. Medical internship, which has always been the basis of clinical quality training in these schools, is done in public or privately insured hospitals that have little or no commitment to teaching. Usually, in these hospitals, the intern is trained by a resident physician or a physician on duty without any preparation for teaching, despite being willing to share his or her knowledge. They end up as low quality medical training courses, whose main purpose is to generate business profit. Acting as diploma factories, these schools train thousands of poorly-prepared doctors who are absorbed into the marked due to the strong demand.

The residency programs have also gone through a crisis that has multiple causes. One is, in fact, the cheap labor that some institutions aim when they open a residency program, as these practitioners work 60 hours per week for a bargain salary. This would not be a big problem if there were trained teachers to guide residents, and/or facilities appropriate for teaching. However, this is the case in only a few institutions that strive to have specialists among their teachers, with master's degrees and doctorates, and a minimum number of hours devoted to teaching.
In addition, the federal government initiated a policy of intervention in residency, signaling to determine which medical specialties will be allowed, the obligation to study up to two years of family practice (according to the specialty chosen), and to allow the opening of indiscriminate residency programs without the proper conditions and the approval or supervision of medical specialty societies.

In view of this, all of us who are committed to medical education, both in undergraduate and residency-level, have been fighting for quality training in large hospitals with qualified teachers; for the lack of mandatory family medicine in all specialties; for the closing of medical schools without adequate educational structure and for the appreciation of the medical profession.

So far, despite the efforts of medical organizations, regional boards and specialty societies, little has been achieved since the struggle against political and financial interests is very uneven across our country. What can we do then, as medical students and residents at this moment, while our aspirations fail to materialize?

Pondering over this, a text by the great Professor Fares Rahal on how to be a good doctor came to my mind. This text was written based on his personal experience as Professor and as a trainer of several generations of doctors in the last fifty years in the Faculty of Medical Sciences of Santa Casa de São Paulo. Below is a summary of the recommendations of this great master of medicine to young people:

"Professional success starts with a calling; it continues with the school attended; the efficiency of the course; dedication to all subjects. Medical residency; the choice of the specialty; respect to ethics and to moral principles; perfect knowledge of one's mother tongue and of two foreign languages; internships in Brazil and abroad; work companionship and, away from work, the Hospitals commonly visited; and family support are also requirements for success. In addition to these factors, participating as assistant in college; doing postgraduate courses; and publishing in academic journals. Having an updated memorial, an office with competent colleagues, in an appropriate location, being recognized as a respected and skilled professional”.

I truly hope that this brief analysis and thoughts may contribute in some way towards improving our dear Brazilian medical practice, so wronged and mistreated in recent times, and guide the youngest on the way to being good doctors.

ELIAS JIRJOSS ILIAS PhD PROFESSOR AT THE SURGERY DEPARTMENT, SANTA CASA DE SÃO PAULO FULL MEMBER OF THE BRAZILIAN COLLEGE OF SURGEONS ASSOCIATE EDITOR AT RAMB http://dx.doi.org/10.1590/1806-9282.60.03.001 